\title{
Isolation and Communication A Stylistic Analysis of Thought Presentation in Mrs. Dalloway
}

\author{
Hua Guo (Corresponding author) \\ College of Foreign Languages and Literatures, Fudan University, China \\ E-mail: guohua@fudan.edu.cn
}

Doi:10.7575/aiac.alls.v.8n.1p.167

Received: 23/10/2016

URL: http://dx.doi.org/10.7575/aiac.alls.v.8n.1p.167

Accepted: 21/01/2017

\begin{abstract}
Mrs. Dalloway by Virginia Woolf is well-acclaimed for its almost non-intrusive portrayal of characters' state of mind. Many studies approach it from biographical, socio-historical, philosophical, and other non-linguistic perspectives, and most linguistic investigations deal with illustrative examples of a single linguistic device in this novel. Few are concerned with the presence of particular linguistic patterns that explain how the intricate flow of thought is successfully depicted. This paper offers a detailed elaboration on the criteria for categorizing thought presentation in Leech\& Short's model and distinguishes cases of ambiguity. A case study of Mrs. Dalloway's flower purchase scene illustrates how different types of thought presentation along with different reporting clauses are used to convey the variation in the character's mental state and the negotiation between her inner voice and the outside world.
\end{abstract}

Keywords: thought presentation, Mrs. Dalloway, stream of consciousness

\section{Introduction}

In the past two hundred years, one of the major concerns of quite many leading writers is how to present vividly the flow of character's thought. The presentation of thought is thus made an essential part of literary texts and in particular is intrinsically linked with what is usually called stream of consciousness writing. Thought presentation in Mrs. Dalloway by Virginia Woolf, has received much attention from literary critics and linguists (e.g. Banfield, 1982; Cohn, 1978; Ehrlich, 1990; Humphrey, 1954; Lambert, 2011; Sotirova, 2013). However, most previous studies are more concerned with non-linguistic aspects of this novel like its psychoanalytical, socio-historical, and philosophical implications (Whitworth, 2015). Linguistic studies are more devoted to the linguistic features of one particular category of thought presentation, free indirect thought, which helps to align the text with the individual character's viewpoint, and other linguistic devices that facilitate the viewpoint shift from one character to another such as connectives (Sotirova, 2004, 2013), parentheticals (Blakemore, 2009). Besides, some stylistic analysts draw examples from this novel as textual support of their thought presentation theories (e.g. Fludernik, 1993; Leech\& Short, 1981; McHale, 1978), but there's no complete analysis exploring the linguistic patterns underlying the thought presentation throughout the novel.

Mrs. Dalloway is mostly comprised of depiction of characters' mental states and conscious thoughts, which are neatly woven together with the unfolding of events in a single day. The focus on characters' consciousness "place[s] extraordinarily high demands on our mind-reading ability" (Zunshine, 2003: 278) and in the meantime enriches our reading experience. Though previous studies do provide invaluable insights into the understanding of Woolf's sophisticated manipulation of thought presentation, few have been devoted to identifying and tracing the development of any particular character's thought. Building on Leech and Short's model, this paper elaborates on the classification of thought presentation modes and conducts a case study of Mrs. Dalloway's flower purchase scene. Variation in her thought presentation pattern indicates changes in her mood and thought as incurred by external events or factors. Moreover, this variation suggests the character's subtle position between the interior and exterior world, thus enhancing the theme of isolation and communication.

\section{Literature review}

Thought presentation forms a substantial part of various text types in both fictional and non-fictional writings. Literary works, however, have been an ever fresh subject for the study of thought presentation, and there are theories (e.g. Chatman, 1978; Fludernik, 1993, 2005; Genette, 1980; Hernadi, 1972; McHale, 1978, 2009; Leech \&Short, 1981; Page, 1988[1973]; Toolan, 2008[1996]) founded with textual support from renowned authors of novels and short stories. The stylistic study of thought presentation is concerned with its effect on the reader and how the effect is manipulated. Researchers usually study thought presentation along a continuum depending on whether the narrator or the character is speaking or both are speaking and a few scalar models have been proposed. Hernadi (1972) might be the first to develop a tripartite scheme consisting of direct, indirect and free indirect speech and thought, with three subcategories of free indirect style identified. Though categories other than these main categories remained unexplained, he perceptively distinguished thought from speech, which used to fall under the generic term speech. The speech presentation scheme 
invented by McHale (1978) is one of the most influential in that it positions the categories along the continuum according to the extent the narrator imitates the character's speech and included categories that are previously considered peripheral. Yet McHale's model is rarely used in actual examination of speech and thought presentation, for its gradational scaling is mostly based on the relative degree of mimesis and does not offer a clear and operational specification for the classification. This paper chooses to develop upon the model of Leech \&Short (1981), which replaces the notion of mimesis with that of the narrator's control over the character's voice and is well accepted for its wide and systematic coverage of speech and thought categories (Ikeo, 2015). As Simpson (1993) notes, it remains "the most accessible introduction to the topic" and "Leech and Short base their categories on explicit linguistic criteria and offer numerous examples from prose fiction in support of their framework" (1993: 21). This explicitness which Simpson mentions ensures the reliability in applying this model to actual stylistic analysis of thought presentation cases.

Leech and Short, followers of the "new stylistics", which applies techniques and concepts of modern linguistics to the study of literature, define stylistics as the study of relation between linguistic forms and artistic functions, and one of its major concerns, as Leech and Short claims, is "to check or validate intuitions"(1981: 5) or personal judgment with which readers automatically respond to the literary text by detailed analysis of the writer's creative manipulation of the linguistic code. In this sense, the examination of language in literary texts is "a mean to a fuller understanding and appreciation of the writer's artistic achievement" (1). To further clarify language for literary use, the object of study in Leech and Short's stylistics, it is necessary to differentiate it from language for daily use. Language for daily use is referential and truth reporting, and the happening it describes can be measured against some absolute reality or actuality of existence, while language for literary use creates and refers to a fictional world of its own and all the events there are a mock reality or potentiality of existence. Stylistics is thus concerned with how and why the writer uses the language to present the realty as it is in the literary text. Needless to say, thought, as part of the mock reality being described, are fictional and serving authorial purposes, but they are particular in that the thinking (internal speech) events are themselves linguistic. And this linguistic nature is what the mystery and beauty of stream of consciousness reside in and why I expect to achieve in-depth understanding of Mrs. Dalloway by thought presentation analysis.

Since no systematic studies about thought presentation in Mrs. Dalloway have been available, I'll mainly look at previous studies that have been conducted about the technique of stream of consciousness in Mrs. Dalloway. Some scholars approach the novel from a biographical and psychoanalytical perspective, which relates its origin and development to Woolf's personal experience and state of mind and regards her literary expression as a fruitful exercise of auto-analysis and self-catharsis. Jouve (2001) sees the psyche as made through dynamic interaction with others, as acting as well as acted upon. He admits that links exist evidently "between the childhood traumas and the insanity, between the insanity and the sensibility, the particular vibration of Woolf's genius" and further endorses Woolf's "alchemical hard work and determination" enabling her to transform the material of madness into material of art, rather than leaving her in insane dreams and evasive from truth (252).

Some perceive it as a historical and social commentary. At the time when Mrs. Dalloway takes place, the once invincible British Empire suffered alarming devastation from World War I with its institutions and values disintegrating and shattering, and understanding and communication became difficult between people who supported traditional English society like the Brutons and those who hoped for continued change like Elizabeth, who were given the possible opportunity to enjoy equal rights with men and the freedom to choose her career path. Besides, there were people split between diverging values like Clarissa and Septimus who found it hard to put life into meaningful connections and felt their personal failures as well as disillusionment with the traditional social order. Whereas Septimus is enforced to "revise and repress" the understanding he has reached during the war (DeMeester, 1998: 661), Clarissa's reaffirmation of her life's meaning is questioned, for "she obstructs meaningful recovery" by "reaffirming a flawed culture" (665), which may suggest Woolf's own deep skepticism about theories of civilization at the time.

Some trace influencing forces upon Woolf's literary creation to her extensive exposure to the "radical intellectual development in philosophy and science" in the Bloomsbury circle like Einstein's relativism (Whitworth, 2001:146). As Whitworth (2015) claims, the distinction between time on the clock and time in the mind, la durée and le temps in Bergson's philosophy, underlines the modernist experiments with time and narrative form (58-59). To truly reflect a rhythmical order emerging out of the chaotic life as people perceive it against imposed system of order like the social hierarchies, Woolf opts out of the formal railway line of sentences and for a non-linear, fluid and fragmentary narrative syntax. Mrs. Dalloway, which apparently follows Big Ben's time sequence when portraying events experienced by an upper-middle class housewife on a party day, actually follows more the heroine's psychological time sequence, which allows the narrative focus to continually shift from the external world to the minds of the characters and from one character's to another's and from one's recollection of the past to his/her anticipation of the future and back to the stark present (Dick, 2001).Thus the traditional plot and description of details that ground the narrative in observable reality often emerge more slowly than they do when presented by an omniscient narrator.

There are still others who mention the post-impressionist artist, Roger Fryer's influence upon Woolf's intuitive and fragmented style of writing. According to Fryer (1998), "the graphic arts are the expression of imaginative life rather than a copy of actual life" (15), which he claims to train people to view the world with mental images as opposed to prescribed representations. Roe (2001) explains in detail Woolf's practice of Fryer's theories and especially her exploration of post-impression's paradox that "subjectivism found expression in surface" (168) with the juxtaposition of Clarissa and Septimus in Mrs. Dalloway, the interior monologue of whom seem to be mirror images of each other. However, Clarissa is radically different from Septimus in that though her thoughts transcend the spatial relations that 
define her, she may always return (e.g. to the party), while Septimus never returns. Roe concludes human sanity consists in knowing that one constructs spaces and locates oneself within and deals with this consequent inability to be omnipotent, while artists, visual or verbal, select and make the part suggest the whole.

Besides, it is necessary to give a brief account of the acknowledged evolution of Mrs. Dalloway. Virginia Woolf first expresses her two assumptions about the reform of traditional realist novel in An Unwritten Novel that novelists must be selective and that the choices made must reflect a shift of focus conveying life not only in its external aspects but also as how it is experienced. Thus the "proper stuff for fiction is the myriad impressions received by the mind exposed to the ordinary course of life". These thoughts give birth to Jacob's room, where two narrative voices and perspectives intermingle without a conventional plot, one impersonal and the other with all limitation of any single viewpoint. To avoid the resultant shadowy characterization, Woolf discovers the psychological "tunneling process" while successfully using "flight of mind" (Dick, 2001:51) in Mrs. Dalloway, by which she tells the past by installment when she has need of it and imitates the selective process by which we know and recollect ourselves, one another and our world.

A review of the major Mrs. Dalloway studies available concerned with portrayal of character's internal state reveals the novel's complexity and profundity, and the various approaches to explain how Woolf develops her technique of stream of consciousness. It's true that they altogether create a panoramic picture of this technique and contribute to the understanding of characterization and theme building. however, they are more concerned with the driving forces that make it happen, the external ones like historical and social forces, the contemporary artistic forces of post-impression and those of realism before, and internal ones like Woolf's own state of mind and perception of reality (including her feministic viewpoint), than with the features that it manifests. Meanwhile, most textual based studies of Mrs. Dalloway go no further than describing features like coexistence of multiple narrative voices, shift of viewpoints and transition from speech to thought, and seldom explains how they are achieved in the linguistic structures underneath. It is necessary to pin down the fleeting stream of consciousness into several well-defined, easy-to-examine categories so that detailed and systematic analysis rather than too general, intuitive and impressionistic reading is possible. Leech\& Short's model of thought presentation provides a linguistic approach to literary texts and has a continuum of categories to break up the stream of consciousness and the multiplicity of viewpoints. Furthermore, though stylistic analysts draw examples from Mrs. Dalloway as textual support of their theoretical framework, there's no complete analysis of all thought presentation throughout the novel and of its overall effect to the portrayal of characters' state of mind and development of theme, where this paper attempts to make a contribution.

\section{Methods}

This paper uses Leech\& Short's model of thought presentation to conduct a stylistic analysis of thought reports in Mrs. Dalloway. In addition to the recognized merits of this model as discussed in section 2, there are reasons to explain why it is appropriate to analyze this novel with this model. To begin with, Mrs. Dalloway is a typical text of thought presentation, for it not only reports what the character thinks, but also successfully renders the character's immediate experience or consciousness of those thoughts. Next, a systematic analysis of thought instances from a single and wellorganized text, rather than of a random selection of thought examples from miscellaneous materials, can better explain large-scale use of thought presentation for strategic purposes. Besides, the relatively uniform style of writing and usage of words in one piece of work makes sense the analysis of correlation between particular reporting verbs and between different categories of thought presentation.

Now some general points can be made regarding the application of this model. Since thought is in fact a form of internalized speech, in other words, speech is a form of externalized thought, and Leech\& Short's model of thought presentation is largely based on the model of speech presentation, this paper will include analysis of some speech presentation in relation with thought presentation. Besides, when applying the model of thought continuum to thought instances in the novel, I will partly rely on quantitative studies and diagram some of the findings like comparison of reporting verbs and thought category distribution between different characters. The variation in the thought presentation pattern can thus be clearly shown.

To be specific, the text Mrs. Dalloway was manually annotated according to Leech \& Short (1981)'s speech and thought presentation model. As shown in Table 1, the main categories of speech presentation are listed and followed by the corresponding set of categories and examples for thought presentation with their respective acronyms provided in the brackets. When tagging the categories, I basically followed the principle of Semino \& Short (2004), but a different set of rules as discussed in 3.2 were applied when cases of ambiguity were examined.

Table 1. Speech and Thought Presentation Scale

Narrative Report of Speech Act (NRSA)
Indirect Speech (IS)
Free Indirect Speech (FIS)
Direct Speech (DS)
Free Direct Speech (FDS)
Narrative Report of Thought Act (NRTA)
Indirect Thought (IT)
Free Indirect Thought (FIT)
Direct Thought (DT)
Free Direct Thought (FDT)


It is necessary to explain why thought reports are categorized so. Leech and Short define different types of thought presentation as categories along a continuum, which are distinguished according to a mixture of criteria, including both formal grammatical and deictic features on the one hand, and functional and pragmatic features on the other. The thought counterparts are distinguished similarly in terms of formal linguistics and deal with the character's mental activities instead of verbal ones.

Thought presentation categories vary according to how strongly they are committed to representing the thought being reported. Suppose thought can be verbalized, in the case of DT, it is usually assumed that "a reporter faithfully represents the original utterance in three aspects: (a) the words and structures used to encode the propositional content, (b) the propositional content and (c) the thought act value."(Short, et al, 1996), while with IT, the reporter's commitment is only limited to two aspects- (b) and (c). Besides this functional difference, IT is also distinguished from DT in formal terms with reported clause subordinated to the reporting clause.

FDT is a freer form than DT in that it is removed of the reporting clause or the quotation marks or both. Since the reported thought in FDT is drawn directly from DT, it has the same commitment to representing the thought that actually takes place as the latter. FIT is a freer form of IT but it differs from IT in a more complex way and there may be ambiguities between FIT and IT and between FIT and narration, which I will explain in 3.2.

NRTA briefly reports what the character thinks without giving the exact words or sentential structures if we suppose they do exist. In formal terms, it differs from other thought categories, DT and IT in particular, in that it does not have subordinate structures following the reporting verb. Its reported thought usually takes the form of nominal phrases after the reporting verb with a proposition in between like "about".

\subsection{Criteria in Distinguishing Cases of Ambiguity}

Of the scale of five speech presentation categories, it is well recognized that only DS can be regarded as a discrete, readily identifiable type, while the others form a cline, ranging from FDS to narrative, with each merging into the next. This is true with thought presentation as well. Besides, functional and pragmatic criteria inevitably involve readers' reception and interpretation of the textual material, we can expect uncertainty and ambiguity in deciding thought categories and I will explain the tagging methods I use in this paper with textual examples if necessary.

I will start from how Leech\& Short define IS and FIS, the basis of defining IT and FIT. They consider FIS a freer rendering of an obviously indirect speech form and define its typical manifestation as one which omits the reporting clause but retains the tense and pronoun selections associated with IS. This definition, however, puts indirect speech forms with both reporting clauses and free features associated with DS in a suspicious status. Let's look at the two examples below:

$$
\begin{aligned}
& \text { e.g. She did not much like parties, Elizabeth said. (p.117) }{ }^{1} \\
& \text { e.g. What department did she want? Elizabeth interrupted. (p.115) }
\end{aligned}
$$

The novel has a predominant majority of inverted constructions, i.e. positioning reported clauses before reporting clauses like the first example.

The second is an example Leech\& Short use to illustrate IS instances where there are more positive freer indications than the first one in the reported clause, the sudden appearance of a reporting clause at the end of the sentence impresses the reader who has so far assumed it as an obvious FIS example with a startling effect.

However, Leech\& Short's FIS definition is somewhat obscure and impractical. They successively make invalid the three traditional, formal criteria that categorize a speech presentation instance as FIS and prefer a functional account where no particular feature has to be present for FIS to occur. Their points do hold good that tense and pronoun selections, rather than restricted to past tense and $3^{\text {rd }}$ person, should be appropriate to the narrative situation in which they appear, thus making possible the occurrence of present tense and $1^{\text {st }}$ person pronoun in FIS, and that even with the presence of the reported clause subordinated to the reporting clause, the selection of lexical and graphological features associated with the original DS can suggest an utterance as FIS. By the very last consideration, the above IS example may as well be designated to FIS, for it doesn't transform the original question to a statement as in usual cases and keeps the original, interrogative flavor of the utterance. This paper categorizes thought presentation between IT and FIT in the same way. The tagging of one thought instance as FIT or IT doesn't merely rely on whether it involves a construction of inversion or not; it is decided by features associated with DT instead.

Besides, the removal of distinction between the reporting clause and the reported clause or even the absence of the former, with features associated with IT in the latter, makes FIT well incorporated into the narration and also leads to the blurring between the two. Here are the major features that distinguish FIT from narration:

a. presence of exclamatory structures in both lexical and syntactical terms indicating character's spontaneous overflow of emotions;

$$
\text { e.g. [...]but it was over. Thank heaven---over. (p.6) }
$$

\footnotetext{
${ }^{1}$ All the quotations of this novel are from Woolf, V. (1978). Mrs. Dalloway. London: Granada.
} 
b. presence of conjunctions, like "for" in particular, which renders what readers might have naturally assumed to be ordinary narrative structures into causal relations and implies character's reasoning process.

This feature is particularly distinctive in the errand of flower purchase scene (5.2). Of the total 15 "for"s found there functioning as conjunction rather than proposition, 10, i.e. $2 / 3$ appeared at the beginning of a sentence, 4 of which further begins a paragraph at the same time.

c. inclusion of explicit character's thought in parentheses indicating the possibility that stretches of words before or after or both are part of the character's ongoing thinking in implicit forms.

$$
\text { e.g.([...]but one must economize, not buy things rashly for Elizabeth). (p.7) }
$$

d. presence of a special form of parenthesis: they said. Since portrayal of character's thought in whatever form always involves an omniscient narrator, who is supposed to know whatever happens in the novel, the reference to information sources other than the narrator like they in the narrative structure might seem redundant, unless interpreted as included in the thought presentation of one particular character, who has limited access to other people's speech he/she isn't directly engaged in.

\subsection{Rules of Quantitative Study}

Considering much of my analysis involves the predominant thought presentation pattern in one part of the novel and the frequency of particular thought presentation categories, I find it necessary to state at the beginning my statistic rules: on the one hand, I decide the major thought presentation pattern of one part by the thought categories with the largest number of sentences; on the other hand, I reply on the natural textual boundaries and have inseparable stretches of thought presentation in one paragraph as one instance; thought presentation in different categories naturally split into two or more instances; thought presentation of one category in one paragraph but with two or more reporting clauses fall into the same number of instances as the reporting clauses. Besides, sentences are separated by full stops and a sentence with semi colons may as well have several instances of thought presentation. By this standard, if more than one reporting clause or thought category occurs in a sentence, the sentences might be fewer than the instances of thought they contain.

e.g. Here she is mending her dress; mending her dress as usual, he thought; here she's been sitting all the time I've been in India; mending her dress; playing about; going to parties; running to the House and back and all that, he thought, growing more and more irritated, more and more agitated, for there's nothing in the world so bad for some women as marriage, he thought; and politics; and having a Conservative husband, like the admirable Richard. (p.38)

The above example contains only one sentence but with five semicolons and the three reporting verbs "thought" indicate at least three instances of thought presentation. This example demonstrates how it is possible to contain more than one instance of thought report in one sentence.

\section{A Case Study: Thought Presentation in the Flower Purchase Scene}

On her way to the florist, Clarissa recollects one girlhood summer at Burton while walking through the bustling London neighborhood this June morning, where she runs into her old friend Hugh, which triggers her successive thoughts of people present in her life and leads her to pondering upon decisions made like to refuse Peter and marry Richard and to preoccupations with aging and death, and in the florist, she partly reconciles herself to the upsurge of emotions in the flowers, when she starts at a car explosion outside.

Examination of this section reveals the absence of DT and IT cases, for one feature essential to the presence of DT, quotation marks (“"), appears only in speech presentations and the feature vital to IT, subordination of reported clauses to reporting clauses, is also absent.

\subsection{Description of Clarissa's thought presentation pattern}

Table 2. Instances of Clarissa's thought presentation in the flower purchase scene

\begin{tabular}{lllll}
\hline Reporting verb/clause & thought & $\begin{array}{l}\text { was } \\
\text { positive/convinced }\end{array}$ & remembered & Total \\
Thought category & 1 & 2 & 0 & 3 \\
\hline FDT & 6 & 1 & 4 & 11 \\
FIT & 7 & 3 & 4 & 14 \\
\hline
\end{tabular}

From the above table, it can be seen that the majority of thought presentation instances with reporting clauses (i.e.11 out of the total 14) are in FIT form. Of these 11 instances of FIT with reporting clauses, 6 instances are signaled by "thought", typical of mental process, 4 instances by "remembered" and 1 instance by the predicative phrase "was positive". On further examination, it's found that, of the 6 "thought" cases, besides one preceding exclamatory 
sentences, the other 5 are followed by narration of character's( Mrs. Dalloway's, to be exact) actions like the following example:

[1]How much she wanted it--that people should look pleased as she came in, Clarissa

thought and turned and walked back towards Bond Street. (p.11)

In other words, they all have the reported clauses before the reporting clauses, thus making it difficult or impossible for the subordination to appear. In this way, not only Mrs. Dalloway's thought is put on par with her actions but is also fore-grounded. Similarly, "was positive" is also located in the middle of a stretch of thought presentation, while in the 4 "remember" cases, this verb is all followed by nominal phrases like "Sylvia, Fred, Sally Seton---such hosts of people", "throwing shillings into the Serpentine", which excludes the possibility of clauses for reported thought as shown in the examples below:

[2][...]but that somehow in the streets of London, on the ebb and flow of things, here, there, she survived, Peter survived, lived in each other, she being part, she was positive, of the trees at home; of the house there, ugly, rambling all to bits and pieces as it was part of people she had never met.(p.10)

[3] She could remember scene after scene at Bourton---Peter furious; Hugh not, of course, his match in any way, but still not a positive imbecile as Peter made out; not a mere barber's block. (p.8)

Moreover, these thought report cases are tinged with directness typical of DT to a greater or lesser degree, like the exclamatory structure in [1] "How much she wanted it", the fragmented structures of two adverbials followed by two short sentences in [2] "here, there, she survived, Peter survived", the colloquial adverbial phrase and nouns in [3]" of course", "a positive imbecile, barber's block", and these features turn what might have been IT into the FIT category.

In comparison with FIT, there are far fewer FDT instances with reporting clauses, altogether 4 instances of this category. Noteworthy, of the 3 instances with reporting verbs or phrases, besides the one with "thought", the rest two both have the word "positive" or "convinced" with a similar meaning to "positive", which reminds us of the above mentioned FIT instances. The frequent appearance of the reporting predicative "was positive" and "was convinced" conveys Mrs. Dalloway's uncertainty about her thought and her effort to assure herself.

\subsection{Implication of Clarissa's thought presentation pattern}

From the above data, it is natural to infer that most thought presentation instances in the opening scene take the FIT form. Since IT is the norm for thought presentation, FIT can be perceived as moving to the right of the norm on the continuum and hence away from the author's most direct control and into the character's active mind (Leech\& Short, 1981: 345). Woolf uses this category of thought presentation most frequently to show readers inside Mrs. Dalloway's mind. As noted in 4.1, these blocks of FIT contain only 10 reporting words, with some in one paragraph, which means quite a number of paragraphs have thought presentation in a freer form without reporting clauses, and FIT effectively integrates Mrs. Dalloway's interminable thoughts into the narration of her short journey to and her stay at the florist. According to Shen (1991), FIT forms tend to have characters' consciousness more naturally blended with the narrator's words, which is conducive to depicting the flow of characters' consciousness under external influences, and at the same time, they are more likely to convey mental states that characters perceive but are not able to articulate in words. The frequent use of FIT cases and the resultant incorporation of thought into narration contribute to the psychoanalytic reading that "without the social scaffolding of discourse", the character is "diffuse, not just internally---subject to the changing currents of impulse and feeling---but externally as well: without firm boundaries, the self merges with its surroundings" (Wyatt, 1986: 120).

Meanwhile, as direct perception of someone else's thought is not possible, FDT is seen as more artificial than FIT and shows characters' thoughts as if they have them verbalized, which renders FDT/DT with a conscious quality. Besides, the present tense in FDT adds to its conspicuity in a narrative in past tense like Mrs. Dalloway. According to Ikeo (2015), the use of FDT makes the reader constantly exposed to the corresponding characters' consciousness, thoughts and viewpoints. This conscious quality and conspicuity in form will contribute to the self-reflective side in Mrs. Dalloway's personality as shown by the reporting predicative "was positive" and "was convinced". Since this section is mainly composed of FIT and FDT, Mrs. Dalloway is represented as more immersed in thought activities, and this is the exact result of Woolf"s "shift in focus from event-driven plots to internally-illuminated character consciousness" (Sotirova, 2013: 26). Though she is also accorded with different types of speech presentation, her speech is largely concentrated on interaction with herself instead of verbal communication with the outside world, which is consistent with Whitworth (2015)'s philosophical interpretation that her world is "an atomized one, in which individuals live in relative isolation" (72), and language, the distinctive feature of mankind that might be expected to overcome isolation is represented as "a ghostly remove" from reality (Banfield, 2000: 157).

The novel begins with a central example of IS:

Mrs. Dalloway said she would buy the flowers herself. (p.5)

The $3^{\text {rd }}$ person pronoun and past tense in reporting clauses, which imply narrator's viewpoint, are characteristics of IS as well as of DS, however, IS is distinguished by its transformation of the original speech into the past tense in reported clauses while sticking to the original's propositional content, speech act value and similar word usages and structures. This blurring or even removal of distinction in tense and person between the reported and reporting and further between speech and narration makes speech an integral part of the narration without removing character's personal involvement 
(like the modal value of "would" implying Mrs. Dalloway's willingness to buy) and imposing on the reader authorial interpretations (as in NRSA). However, this "IS" is followed by a succession of Mrs. Dalloway's FIT with the conjunction "for" as shown below, which informs readers that this IS is part of FIT with her self-reference as "Mrs. Dalloway", as if she reviews her speech disinterested, thus contrasting her introverted, reflective self and her extroverted, outgoing self in social life:

For Lucy had her work cut out for her. The doors would be taken off their hinges; Rumpelmayer's men were coming. And then, thought Clarissa Dalloway, what a morning--fresh as if issued to children on a beach. (p.5)

Mrs. Dalloway explains why she will go to buy flowers herself in the clause beginning with "for" and the combination of conjunction and adverbial "and then" connects sentences before and after this combination and indicates they both belong to the FIT category as explicitly signaled by the reporting verb "thought" immediately after this combination, which is followed by a reported thought in the form of a exclamatory sentence and further by a fresh new paragraph of reported thought as below:

What a lark! What a plunge! For so it had always seemed to her, when, with a little squeak of the hinges, which she could hear now, she had burst open the French windows and plunged at Bourton into the open air. How fresh, how calm, stiller than this of course, the air was in the early morning; like the flap of a wave; the kiss of a wave; chill and sharp and yet (for a girl of eighteen as she then was) solemn, feeling as she did, standing there at the open window, that something awful was about to happen. (p.1)

The contact of nature plunges Mrs. Dalloway into happy thoughts, as reflected in two consecutive exclamations, and into recollection of girlhood in short phrases quickly moving on after another conjunction "for", with near deictic like "so", "now", "this" reinforcing the directness and vividness of FIT, from which we find Mrs. Dalloway never really emerges in this section, though apparently interrupted by two speech events and several stretches of narrations. For example, her encounter with Hugh begins with DS, which quickly slips into a mixture of FIT and FIS, and even this one-round DS does not really connect.

"Good-morning to you, Clarissa!" said Hugh, rather extravagantly, for they had known each other as children. "Where are you off to?"

"I love walking in London," said Mrs. Dalloway. "Really it's better than walking in the country." (p.7)

"I love walking in London" is Mrs. Dalloway's verbal expression of emotions rather than in response to Hugh's greeting and question, or we can interpret this disconnectedness as Woolf's intention to omit something and have the most essential message communicated, for this remark echoes Mrs. Dalloway's thought presented earlier in this section, which expresses her love for the hustle and bustle of London urban life:

In people's eyes, in the swing, tramp, and trudge; in the bellow and the uproar; the carriages, motor cars, omnibuses, vans, sandwich men shuffling and swinging; brass bands; barrel organs; in the triumph and the jingle and the strange high singing of some aeroplane overhead was what she loved; life; London; this moment of June. (p.6)

The other of her conversation at the florist's, is reduced to the minimal speech form, "[...] as she stood talking to Miss Pym"(p.7), and readers are only informed of the occurrence of the speech event and the people involved, but know nothing about the propositional content, let alone the exact words and sentences used. This pervasiveness and dominance of FIT may as well be understood as Virginia Woolf's portrayal of Mrs. Dalloway to the effect that the interior world is more real and more important than the exterior to her. Besides, this section has quite some questions Mrs. Dalloway asks herself, which is also features of FIT and I will discuss below. For example, she wonders in the presence of Hugh,

Not the right hat for the early morning, was that it? (p.7)

The mental process of her self-questioning is also represented in indicative word order as in the example "so she would still find herself arguing in St. James's Park, still making out that she had been right--and she had too--not to marry him" (p.9). Considering her careless and inattentive conversation with others as discussed above, we can find Mrs. Dalloway is more concentrated on interaction with herself than with others.

Woolf does include other speech forms, mostly FIS, to indicate Mrs. Dalloway's contact with others, but these do not truly represent her verbal interaction with others, rather, they are snatches of others' speech impressed on her mind, which are used as a portion of FIT to show her concern about others' opinions about people and events around her as well as of herself. For example, she relates her judgment about the relationship between her daughter Elizabeth and Miss Kilman to Mr. Dalloway's evaluative words:

But it might be only a phase, as Richard said, such as girls go through. (p.12)

One must make allowances for that, and Richard said she was very able, had a really historical mind. (p.12)

Both are typical FIS instances but embedded in FIT. Mrs. Dalloway compares her own feelings and thinking with others', weigh and consider if others' makes sense in attempt to get rid of her monstrous hatred towards Miss Kilman. 
The case is quite similar when Mrs. Dalloway thinks of Peter's and her neighbor's words, as both are presented in FIS with "Peter said" and "they said" respectively as the reporting clause. The use of FIS inside FIT conforms to Mrs. Dalloway's self-confession that she does things not simply for themselves "but to make people think this or that" (p.11). As Roberts (1946) comments, the audience's pleasure derives not from recognizing the objects or people represented, but from the recognition of "inevitability in relations" (836-837), dialogues are resonated, explored and interpreted by the speaker or other observing characters' perceptions and thought presentation (Ikeo, 2015), and Mrs. Dalloway's dominant status as well as the multiplicity of viewpoints is established.

This internal communication is also evidenced by several of Mrs. Dalloway's monologues represented in DS:

Nonsense, nonsense! she cried to herself, pushing through the swing doors of Mulberry's the florist. (p13)

And as she began to go with Miss Pym from jar to jar, choosing, nonsense, nonsense, she said to herself, more and more gently, as if this beauty, this scent, this colour, and Miss Pym liking her, trusting her, were a wave which she let flow over her and surmount that hatred, that monster, surmount it all . (p.14)

In the above two instances, where the reported speech is positioned before the reported clause, Mrs. Dalloway's spontaneous expression of emotions is foregrounded. The first instance which starts and constitutes a paragraph alone confronts readers with the intensity of Mrs. Dalloway's interjection and her determination to tame her emotions, the hatred to Miss Kilman in particular, while the location of the second instance in the middle of the narration greatly reduces this intensity. Besides, the changes of the reporting verb from a more emotional verb "cried" to a more ordinary one "said" and of the punctuation marks from exclamation marks to commas, together with the supplementary description of the second instance including the adverbial "more and more gently" and the subjunctive mood sentence "as if to surmount it all” indicate Mrs. Dalloway's gradual freeness from her emotions.

Besides near deictic such as "so", "now" and exclamatory structures, many interrogative structures also indicate the presence of FIT. Altogether 10 instances of questions are found, among which are 3 "was that it" to check her memory, 1 rhetorical question and all the rest are wh-questions demanding herself to answer. As "the central problem" in Woolf's fiction "is intimately related" "to the problem of death", and "the ultimate separation"(Naremore, 1973: 102), Mrs. Dalloway's love for life is eroded by a sense of impending tragedy from the first page of the novel and she's obsessed with her query of life's meaning and the absolute threat of mortality ever since.

However, she's not so passive and feeble as to be taken over by the sense of uncertainty and menace from life. She is fighting to get control and be sure of herself. Of the 5 instances of FDT found, 2 involve the predicative "was/felt positive" and 1 "was convinced", which represents her self-confidence, or rather, her effort to persuade herself to have confidence in herself and in her interpretation of life. The FDT category, a freer form of DT with the least authorial intervention, where as if the character speaks their thought in the presence of the reader, renders her thought with a more conscious quality, as if Mrs. Dalloway could hardly assure herself unless she speaks up her thought, as reflected in the monologue DS instance: "That is all," she said, looking at the fishmonger's. "'That is all,' she repeated."(p.12) Her self-control is also reflected in reporting clauses. As noted earlier, 5 of the 10 FIS instances with reporting clauses have narration of Mrs. Dalloway's action immediately after the reporting verb "thought", as in examples "[...] Clarissa thought, turned and walked back towards Bond Street and [...] she thought, stepping on the pavement" (p.11), thus creating the effect that she turns from the mental world to the realistic one, from the "mind time" to the "actual time", pulls herself together and moves on. Whereas this testifies to the novel's "swift reorientation of the perspectival focus" (Sotirova, 2013: 138), it also confirms Dick (2001)'s claim that despite her celebration of the vision of life, the author "would not abandon material reality, the integral part of the other, more profound, reality she wishes to explore" (71). Myriads of visions are ingeniously threaded through factual experience and Mrs. Ramsay's affirmation of life is thus reinforced.

\section{Conclusion}

Using Leech \& Short's model of thought presentation, this paper offers a detailed elaboration on the criteria for categorizing thought presentation and distinguishing cases of ambiguity. The flower purchase scene is used to illustrate how the sophisticated manipulation of thought presentation contributes to the portrayal of the character's flow of thought and the changes in the character's predominant thought pattern. The opening section lays down the foundation of FIT and FDT for the whole novel ever since the opening sentence, with external events triggering off rounds of rounds of thought. The positioning of the reported thought before the reporting clause is used to fore-ground the spontaneous overflow of Mrs. Dalloway's emotions, which runs throughout the novel. Mrs. Dalloway's thought is mainly presented in FIT, FIT without reporting verbs in particular, with features like near deictic, exclamatory and fragmented structures indicating freeness in comparison with IT and conveys her happy thoughts about girlhood memories and love for London urban life at present, while the interrogative forms in FIT reflects Mrs. Dalloway's selfreflective side in contrast with her outgoing social side and her obsession with the gloomy thoughts of aging and death. While FIT, the majority of which are signaled by reporting verbs like "thought" and "remembered", reports more of the associations Mrs. Dalloway has with the past as well as with the present, FDT, mostly signaled by the reporting predicative "was/felt positive" shows more of her conscious effort to baffle against the threat of mortality and have confidence in life. Mrs. Dalloway is also accorded with speech presentation, like FIS, but they are externalized thoughts rather than true communications and her monologues in DS explicitly reflect her internal communication. In this way, we have a much clearer picture of the character's thought presentation patterns and their implication to the novel's characterization and theme building. Admittedly, we can never decide the significance and interpretation of the novel 
by these stylistic features alone. A fuller understanding and interpretation rely on other relevant research findings as reviewed in the literature survey as well as any other textual information of the novel that are possibly not mentioned in this paper.

\section{References}

Banfield, A. (1982). Unspeakable Sentences: Narration and Representation in the Language of Fiction. Boston: Routledge \& Kegan Paul.

Banfield, A. (2000). The Phantom Table: Woolf, Fry, Russell and the Epistemology of Modernism. Cambridge: Cambridge University Press.

Blakemore, D. (2009). Parentheticals and point of view in free indirect style. Language and Literature, 18(2), $129-153$. Chatman, S. (1978). Story and Discourse: Narrative Structure in Fiction and Film. Ithaca: Cornell University Press.

Cohn, D. (1978). Transparent Minds: Narrative Modes for Presenting Consciousness in Fiction. Princeton: Princeton University Press, 1978.

DeMeester, K. (1998). Trauma and recovery in Virginia Woolf's Mrs. Dalloway. MFS: Modern Fiction Studies, 44(3), 649-673.

Dick, S. (2001). Literary realism in Mrs. Dalloway, To the lighthouse, Orlando and the Waves. In Roe, S. \& S. Sellers (Eds.), The Cambridge Companion to Virginia Woolf (pp.50-71). Shanghai: Shanghai Foreign Language Education Press.

Ehrlich, S. (1990). Point of View: A Linguistic Analysis of Literary Style. London: Routledge.

Fludernik, M. (1993). The Fictions of Language and the Languages of Fiction. London: Routledge.

Fludernik, M. (2005). Speech presentation. In D. Herman et al (Eds.), Routledge Encyclopedia of Narrative Theory (pp. 558-563). London \& New York: Routledge.

Fryer, R. (1998). Vision and Design. London: Dover.

Hernadi, P. (1972). Dual perspective: Free indirect discourse and related techniques. Comparative Literature, $24,32-43$. Humphrey, R. (1954). Stream of Consciousness in the Modern Novel. Berkeley: University of California Press.

Ikeo, R. (2015).Speech and thought presentation. In V. Sotirova (Ed.), The Bloomsbury Companion to Stylistics (pp. 356-379). London: Bloomsbury.

Jouve, N. W. (2001). Virginia Woolf and psychoanalysis. In Roe, S. \& S. Sellers (Eds.), The Cambridge Companion to Virginia Woolf (pp.245-272). Shanghai: Shanghai Foreign Language Education Press.

Lambert, D. (2011). The Shifting Points of View in Virginia Woolf's Novel Mrs. Dalloway: Rooms,

Corridors, and Houses. Lewiston, NY: Edwin Mellen Press.

Leech, G. N., \& Short, M. H. (1981). Style in Fiction---A Linguistic Introduction to English Fictional Prose. New York: Longman.

McHale, B. (1978). Free indirect discourse: A survey of recent accounts. PTL, 3, 249-278.

McHale, B. (2009). Speech representation. In P. Huhn et al. (Eds.), Handbook of Narratology (pp. 249-287). Berlin \& New York: Walter de Gruyter.

Naremore, J. (1973).World without a Self: Virginia Woolf and the Novel. New Haven: Yale University Press.

Page, N. 1988[1973].Speech in the English Novel. London: Longman.

Roberts, J. H. (1946). "Vision and Design” in Virginia Woolf. PMLA, 61, 835-847.

Roe, S. (2001). The impact of post-impressionism. In Roe, S. \& S. Sellers (Eds.), The Cambridge Companion to Virginia Woolf (pp. 164-190). Shanghai: Shanghai Foreign Language Education Press.

Semino, E., \& Short, M. (2004). Corpus Stylistics: Speech, Writing, and Thought Presentation in an English Corpus of Writing. London: Routledge.

Shen, D. (1991). Reevalution of functions of free indirect speech. Foreign Language Teaching and Research, 2, 11-16.

Short, M., Semino, E., \& Culpeper, J. (1996). Using a corpus for stylistics research: speech and thought presentation. In Thomas, J. \& M. Short (Eds.), Using Corpora in Language Research. London: Longman.

Simpson, P. (1993). Language, Ideology and Point of View. London: Routledge.

Sotirova, V. (2004). Connectives in free indirect style: Continuity or shift? Language and Literature, 13(3), $216-234$.

Sotirova, V. (2013). Consciousness in Modernist Fiction: A Stylistic Study. Basingstoke: Palgrave Macmillan.

Toolan, M. (2008[1996]). Language in Literature: An Introduction to Stylistics. Beijing: Foreign Language Teaching and Research Press.

Whitworth, M. (2001). Virginia Woolf and modernism. In Roe, S. \& S. Sellers (Eds.), The Cambridge Companion to Virginia Woolf (pp.146-163). Shanghai: Shanghai Foreign Language Education Press.

Whitworth, M. (2015). Virginia Woolf: Mrs. Dalloway. London: Palgrave.

Woolf, V. (1978). Mrs. Dalloway. London: Granada.

Wyatt, J. (1986). Avoiding self-definition: In defense of women's right to merge (Julia Kristeva and Mrs. Dalloway). Women's Studies, 13, 115-126.

Zunshine, L. (2003). Theory of mind and experimental representations of fictional consciousness. Narrative, 11(3), 270-291. 